\title{
Training and expertise in undertaking assisted vaginal delivery (AVD): a mixed methods systematic review of practitioners views and experiences
}

\author{
Claire Feeley $^{1^{*}}$ (1), Nicola Crossland ${ }^{1}$, Ana Pila Betran ${ }^{2}$, Andrew Weeks ${ }^{3}$, Soo Downe ${ }^{1}$ and Carol Kingdon ${ }^{1}$
}

\begin{abstract}
Background: During childbirth, complications may arise which necessitate an expedited delivery of the fetus. One option is instrumental assistance (forceps or a vacuum-cup), which, if used with skill and sensitivity, can improve maternal/neonatal outcomes. This review aimed to understand the core competencies and expertise required for skilled use in AVD in conjunction with reviewing potential barriers and facilitators to gaining competency and expertise, from the point of view of maternity care practitioners, funders and policy makers.

Methods: A mixed methods systematic review was undertaken in five databases. Inclusion criteria were primary studies reporting views, opinions, perspectives and experiences of the target group in relation to the expertise, training, behaviours and competencies required for optimal AVD, barriers and facilitators to achieving practitioner competencies, and to the implementation of appropriate training. Quality appraisal was carried out on included studies. A mixed-methods convergent synthesis was carried out, and the findings were subjected to GRADE-CERQual assessment of confidence.
\end{abstract}

Results: 31 papers, reporting on 27 studies and published 1985-2020 were included. Studies included qualitative designs (3), mixed methods (3), and quantitative surveys (21). The majority (23) were from high-income countries, two from upper-middle income countries, one from a lower-income country: one survey included 111 low-middle countries. Confidence in the 10 statements of findings was mostly low, with one exception (moderate confidence). The review found that AVD competency comprises of inter-related skill sets including non-technical skills (e.g. behaviours), general clinical skills; and specific technical skills associated with particular instrument use. We found that practitioners needed and welcomed additional specific training, where a combination of teaching methods were used, to gain skills and confidence in this field. Clinical mentorship, and observing others confidently using the full range of instruments, was also required, and valued, to develop competency and expertise in AVD. However, concerns regarding poor outcomes and litigation were also raised.

Conclusion: Access to specific AVD training, using a combination of teaching methods, complements, but does not replace, close clinical mentorship from experts who are positive about AVD, and opportunities to practice emerging AVD skills with supportive supervision. Further research is required to ascertain effective modalities for wider training, education, and supportive supervision for optimal AVD use.

*Correspondence: cfeeley@uclan.ac.uk

1 School of Community Health and Midwifery, University of Central Lancashire, Preston PR1 2HE, UK

Full list of author information is available at the end of the article permits use, sharing, adaptation, distribution and reproduction in any medium or format, as long as you give appropriate credit to the original author(s) and the source, provide a link to the Creative Commons licence, and indicate if changes were made. The images or other third party material in this article are included in the article's Creative Commons licence, unless indicated otherwise in a credit line to the material. If material is not included in the article's Creative Commons licence and your intended use is not permitted by statutory regulation or exceeds the permitted use, you will need to obtain permission directly from the copyright holder. To view a copy of this licence, visit http://creativecommons.org/licenses/by/4.0/. The Creative Commons Public Domain Dedication waiver (http://creativeco mmons.org/publicdomain/zero/1.0/) applies to the data made available in this article, unless otherwise stated in a credit line to the data. 


\section{Plain language summary}

During the late stages of childbirth, complications can occur which require rapid birth of the baby. This can be facilitated with instruments (usually forceps or a suction cup) or by surgery (caesarean section). In some circumstances, instrumental birth (also termed assisted vaginal delivery, AVD) may be a better option than caesarean section. AVD requires practitioners to develop skills, competence and expertise in the procedure. Our aim for this review was to examine practitioners', funders' and policy makers' views about competence and expertise in AVD, how they can best gain this, the barriers and facilitators to implementing training packages, and their views, opinions and perspectives of their training. We included 27 studies (published 1985-2020), mostly from high-income countries. We had moderate confidence on one findings statement, with the rest assessed with low confidence. We found that practitioners valued extra training in AVD, observing others using the different instruments, and opportunities for clinical supervision, mentorship to gain experience, competence and expertise. We also found that, from the practitioners' perspective, competence encompasses a number of inter-related skill sets; non-technical skills (e.g. effective communication with the labouring woman), broad clinical skills (e.g. capacity to assess the whole clinical picture) and technical instrumental skills (e.g. correct application of a vacuum cup to the fetal head, or capacity to turn the baby so it is in the right position). Practitioners also identified a number of barriers and facilitators that supported (or did not support) their training needs and development.

Keywords: Assisted vaginal birth, Assisted vaginal delivery, Competence, Training, Practitioners

\section{Background}

Instrumental births mainly involve the use of forceps or a vacuum cup to expedite a birth, usually in situations of fetal compromise or for maternal benefit $[1,2]$. Also known as 'assisted vaginal delivery' (AVD), it is a valuable tool during late second stage of labour where performing a caesarean section may not be possible, or safe, or acceptable to the woman [1,2]. The prevalence of AVD use varies widely, both internationally and within countries [3]. However, as techniques of caesarean section have improved and become safer in the last few decades, in some contexts, the use of AVD has been substantially reduced in favour of caesarean section [1]. In some contexts low rates of AVD use occurs in parallel with overuse of caesarean sections, raising concerns about excess maternal morbidity or mortality due to unnecessary or unconsented surgery $[1,4]$. In other contexts, low use of AVD and poor access to safe caesareans are associated with poorer neonatal outcomes, due to lack of access to safe and acceptable methods for managing maternal or fetal emergencies [1]. Forceps and vacuum births can both be undertaken safely, but concerns have been raised regarding inappropriate decision making about when to use them, and sub-standard levels of technical skills or training can cause iatrogenic harm. This could disincentivize their use in favor of a caesarean section (if this is option is possible) or even be a barrier to their use where they are the only technical solution available $[1,4,5]$.
Skilled AVD use is recommended by the World Health Organization (WHO) as a safe alternative to caesarean section rates and as a means to improve maternal and neonatal outcomes when certain complications arise [2, 4]. Indeed, important improvements in fetal outcomes have been reported when optimal instrumental birth options are introduced into LMIC settings [1]. Our previous review [6] focused on women's, partners' and healthcare providers' views and experiences of AVD. We found that views and experiences of AVD tended to fall somewhere between extremes [6]. Where indicated, AVD can be an effective, acceptable alternative to caesarean section. However, for childbearing women, the experience of AVD could be negatively impacted by the unexpected nature of events that precipitated their use. Particularly in high-income settings, this was associated with unmet expectations [6]. We also found that positive relationships, good communication, involvement in decisionmaking, and (believing in) the reason for intervention were important mediators of birth experience. Additionally, from the perspectives of professionals, attitudes and skills were simultaneously barriers (where substandard) and facilitators (where they were of high quality) for the acceptability of using AVD.

The aim of the current review was to improve the understanding of limitations, barriers and potential facilitating factors relating to expertise, training and 
competencies in AVD, from the perspective of maternity care practitioners, funders and policy makers.

The objectives of the review were to establish:

1. What expertise, training and competencies are required for optimal use of AVD?

2. What are the barriers and facilitators to achieving these levels of expertise and competence?

3. What are the barriers and facilitators to implementation of appropriate training?

4. What are practitioner views, opinions, perspectives and experiences on training for use of AVD?

\section{Methods}

We used a systematic integrated mixed-methods design with the protocol published prior to commencing the review [7]. The review was carried out according to the protocol with the following exceptions: we were unable to undertake the planned meta-thematic synthesis due to the few qualitative studies found, and the low quantity and/or quality of the data presented in them. Due to this factor, we were also not able to carry out the pre-planned convergence matrix to assess the similarities/dissimilarities of findings between survey and qualitative data [7]. Therefore, we adopted a mixed-methods integrated review design, as per Noyes et al. [8]. This involved using both quantitative survey and qualitative data that was integrated to answer the research questions.

\section{Criteria for inclusion}

Our focus was on the views, opinions, perspectives and experiences of maternity care providers, maternity funders and policy makers regarding the expertise, training and competencies required for optimal AVD. We also sought to examine the barriers and facilitators to achieving practitioner competencies and the implementation of appropriate training. We included primary studies that reported participants' views, beliefs, concerns and experiences. These included studies using qualitative designs (e.g. ethnography, phenomenology) or qualitative methods for data collection (e.g. focus group interviews, individual interviews, observation, diaries, oral histories) and studies using quantitative designs such as surveys (e.g. questionnaires), or mixed methods approaches. There were no language restrictions. Searches were carried out from the inception data of each database, due to the potential value in examining historic use of instruments for expediting birth. Studies with a principle focus on breech presentation, multiple pregnancies, or where the lie of the fetus was transverse or oblique, or where participants were experiencing preterm birth, were excluded.

\section{Reflexivity}

Transparent reflexivity throughout qualitative research is central to good practice [9]. Our interdisciplinary research team considered our potential biases prior to, and throughout the review to reduce potential impact upon the findings. CF and SD are midwives with extensive clinical experience, $\mathrm{CK}$ is a sociologist and all three have many years' experience of maternity care research. All three believe that AVD can be a positive experience for women, if done well, with skill and with respect for women. However, all three recognise that it can be distressing and damaging if carried out without skill, respect and compassion. NC, is a health researcher who held prior beliefs about the importance of respectful care and communication for women throughout the maternity episode including AVD. ADW is an obstetrician who has practiced AVD in both the UK and Uganda over the last 25 years. He has seen perinatal deaths prevented by it, and debriefed women who have suffered trauma from it. He therefore sees both its potential benefits and harms, and believes that personal teaching and mentoring is critical to a good outcome. His personal preference is for routine ultrasound to determine fetal head position, nonrotational forceps and manual rotation when required. He uses vacuum only for 'outlet procedures'. APB is a medical officer with 20 years of experience in maternal and perinatal health research and public health, who held prior beliefs about the importance of women having the right to evidence-based and respectful maternity care and that narrowing worldwide disparities is crucial, including disparities in the appropriate and respectful use of AVD for improved outcomes.

\section{Search strategy}

A predesigned search strategy included pilot searching and information specialist input to ensure a robust approach. Systematic searches were carried out in March/April 2020 in MEDLINE, CINAHL, PyschInfo, EMBASE and Global Index Medicus (that included AJOL and LILACS databases). Searches were carried out using keywords (see Table 1) for the Population, Intervention and Outcomes adapted as necessary for the individual database i.e. using $\mathrm{MeSH}$ terms. An example search strategy is shown in Additional file 1: example search strategy. Additional searches were carried out, including reference checking of the included studies, crosschecking with Google Scholar and reference checking of key international guidelines (The International Federation of Gynecology and Obstetrics, The Royal College of Obstetricians and Gynaecologists, The American College of Obstetricians and Gynecologists, The Society of Obstetricians and Gynecologists of Canada, The Royal 
Table 1 Search terms

Midwife or midwives or midwifery or nurse-midwife or obstetrician or doctor or physician or dr or ob or obstetrics or nurse-midwives or obstetric nurse or nurse or trainee or registrar or practitioner or personnel or resident or medical officer or medical or provider or worker or specialist or attendant or graduate or professional or intern

Assisted vaginal delivery or assisted vaginal birth or ventouse or vacuum or kiwi or extraction or vacuum assisted delivery or forceps delivery or instrumental delivery or instrumental birth

Skill* or knowledge or competence or train* or education or expertise or instruction

Australian and New Zealand College of Obstetricians and Gynaecologists).

\section{Study selection}

Records were collated into Covidence systematic review software [10] and duplicates removed. Each title and abstract was screened against the inclusion/exclusion criteria by the lead author (CF) and screened independently by one of three reviewers (CK, NC, APB). At fulltext stage, each record was screened by the lead author (CF) and screened independently by one of two reviewers (NC, CK). Discrepancies were resolved by consensus. The final list of included studies agreed among the reviewers.

\section{Data extraction and quality assessment}

Study characteristics of the included papers were collected on a data extraction form: author \& date, title, resource setting, country, study design, setting, population, participants, methods. Quality assessment of quantitative surveys was carried out using a critical appraisal checklist [11]. Quality assessment of qualitative studies was carried out using criteria from Walsh \& Downe [12]. Quality assessment of mixed methods studies was carried out using the Mixed Methods Appraisal Tool (MMAT) tool [13]. All studies were graded A-D by discussion between two reviewers $(\mathrm{CF} / \mathrm{NC})$, where A: No, or few flaws; the study credibility, transferability, dependability, and confirmability is high, and D: Significant flaws that are very likely to affect the credibility, transferability, dependability, and/or confirmability of the study [14]. No disagreements were noted, and no study was excluded on the basis of quality as per our protocol. A detailed exposition of the quality assessments can be found in Additional file 2: QA.

\section{Data synthesis}

A data-based convergent synthesis [8] was carried out; whereby all of the included studies were analysed and synthesised using the same methods. This involved extracting the findings data from each paper in short relevant sections (as opposed to line-by-line coding, or statistical extraction) and tabulating. The data across the studies were then grouped as initial descriptive themes in relation to the research question (1-4). A second iteration refined these further to ensure the descriptions captured the data adequately and generated 'Statements of Findings'. These were subjected to GRADE-CerQual assessments [15] which indicate the degree of confidence to be placed in each findings statements. Assessments included minor, moderate, or substantial concerns regarding four domains: 1 . methodological limitations of included studies; 2 . relevance of the included studies to the review question; 3 . coherence of the review finding; and 4. adequacy of the data contributing to a review finding. Then, based on an overall assessment of these four domains, confidence in the evidence for each review finding was assessed as high, moderate, low or very low [15]. As per Noyes et al. [8], data transformation in this instance was 'qualitised' as in, the findings are presented narratively. A detailed exposition of the data extraction can be found in Additional file 3: data extraction.

\section{Results}

From the searches, 12,623 hits were identified, and one further study was identified from an additional source. After 4389 duplicates were removed, 8064 records were discarded as irrelevant after reviewing title and abstract. Of 171 full-text papers screened, 140 records were excluded, with 31 papers [16-46] included into the review as shown in Fig. 1: PRISMA. No studies were found from the perspectives of funders or policy makers.

Of the 140 excluded records, 35 studies were on topic, but the wrong study design for example, pre/post-test training quasi-experimental studies. Details of all the excluded studies, and the reasons for exclusion can be found in Additional file 4: excluded studies.

Of note, the 31 included papers, several were from the same study $(\mathrm{n}=4[18-21], \mathrm{n}=2[35,43])$, therefore, 27 studies were quality assessed, analysed and synthesised. Table 2 gives an overview of the characteristics and quality assessment of all included studies.

The 27 studies included $\mathrm{n}=3$ qualitative $[18-21,29,35$, 43], $\mathrm{n}=3$ mixed methods [17, 41, 45], $\mathrm{n}=21$ quantitative survey designs $[15,19,21-25,27,29-33,35-39,41,43$, 45]. The majority were undertaken in high-income countries $(n=23)$, two were from upper-middle income countries $[27,40]$, one was from a lower-income county [29] and one survey included 111 low-middle countries [30]. The earliest study was 1985 [34] and the most recent was published in 2020 [32]. The studies included participants that were: trainee obstetricians $[16,23,25,26,31,33,34$, $36,39,42,47]$, recent obstetric graduates [40, 41], obstetricians [22, 24, 32, 35, 37, 38, 43], GP/family medicine 


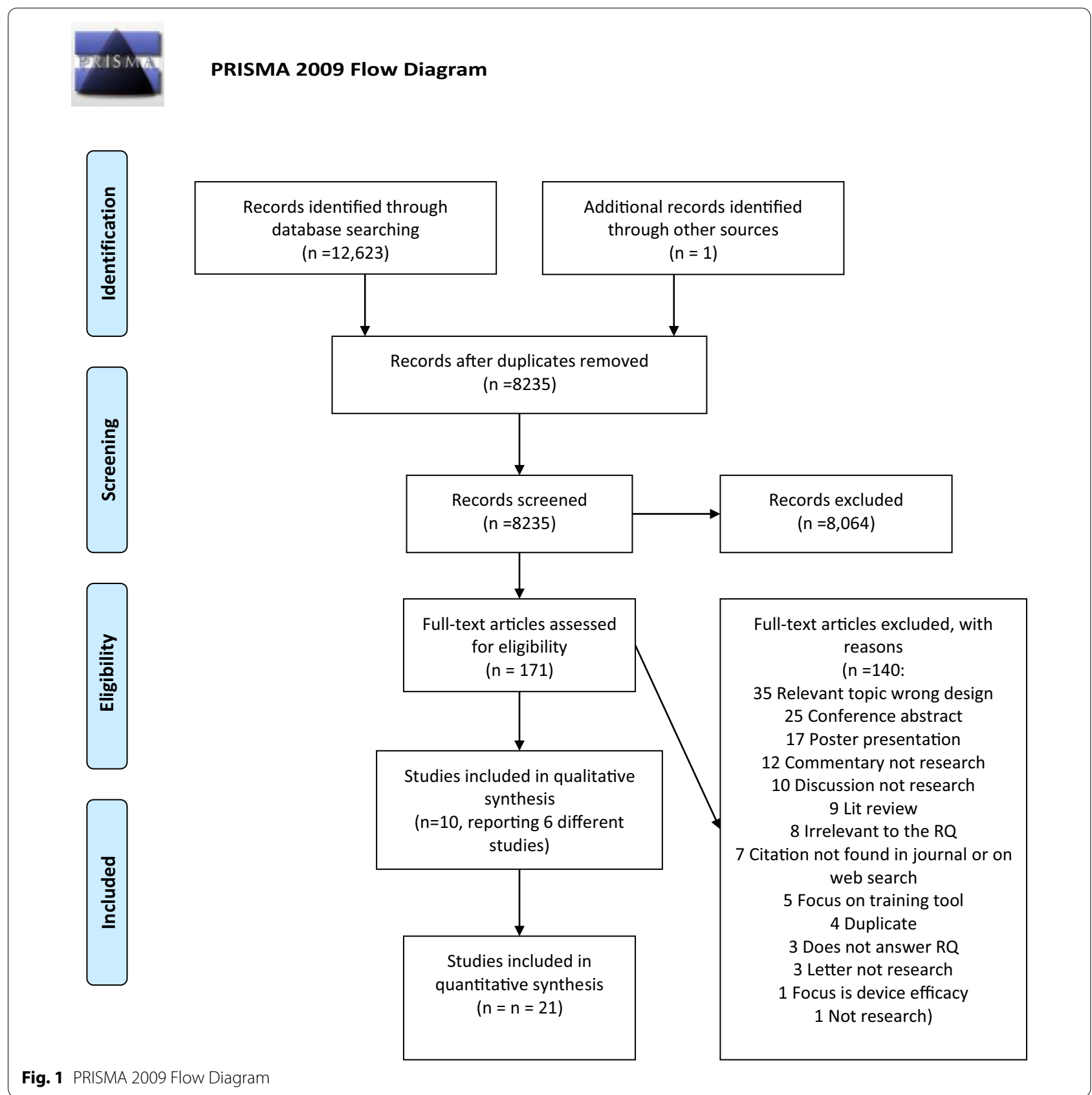

doctors [44, 46], midwives [17], medical officers [29], and multi-professional participants [18-21, 27, 45]. The quality of the included papers was generally poor whereby the majority of the survey studies scored C or C/D.

The convergent synthesis generated the descriptive themes and Statements of Findings (SoFs) -the development is shown in Table 2. Table 3 shows the summary of review findings and associated CERQual assessments (Table 4).
What expertise, training and competencies are required for optimal use of AVD?

Three SoF's were relevant to this question (all with low confidence), they related to non-technical, broader clinical and technical AVD skills.

\section{Expertise in non-technical skills}

Five studies [17, 19, 21, 41, 43] highlighted non-technical skills that included behaviours associated with demonstrating capability through confidence, situational 
Feeley et al. Reprod Health $\quad$ (2021) 18:92

Page 6 of 22

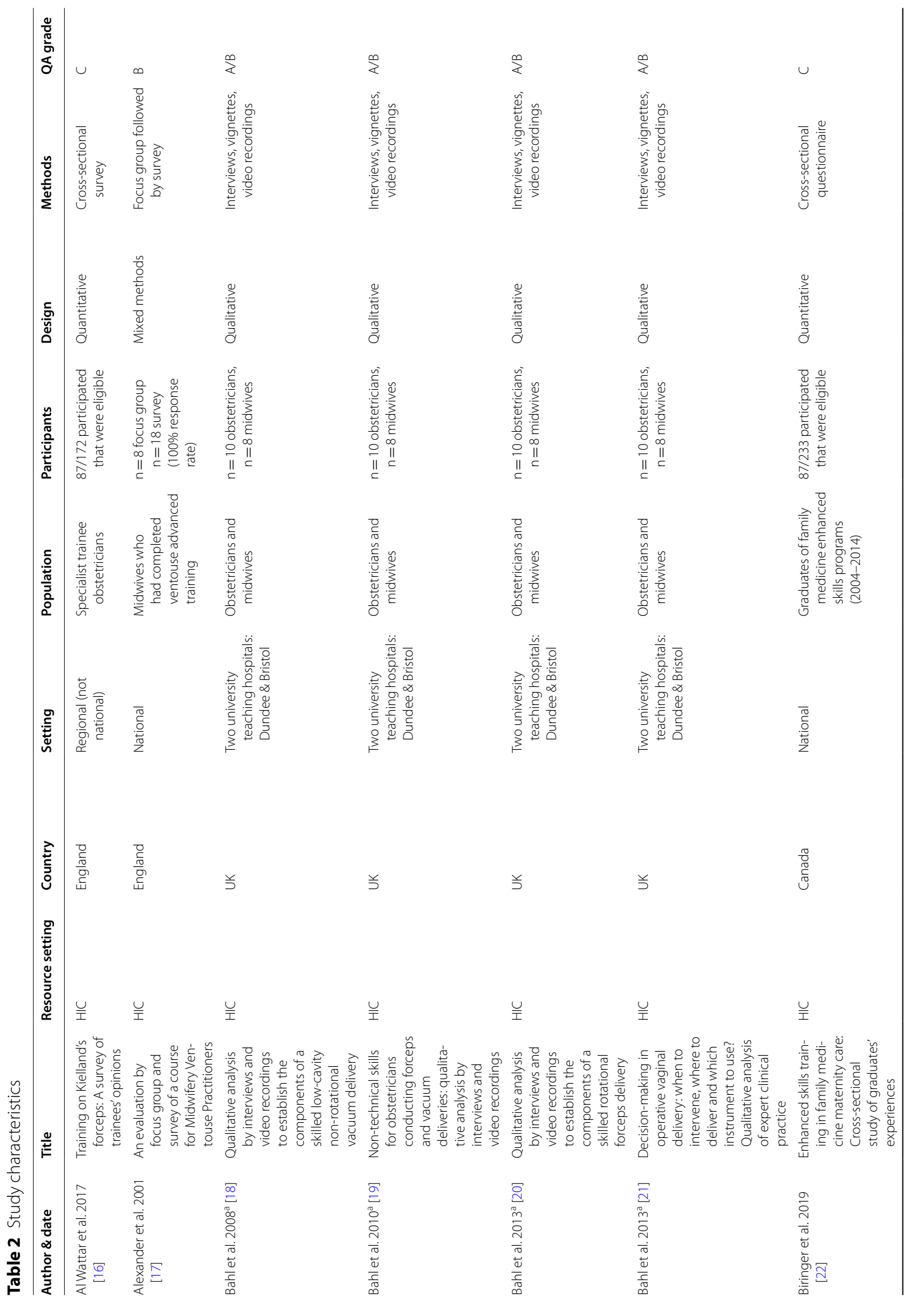




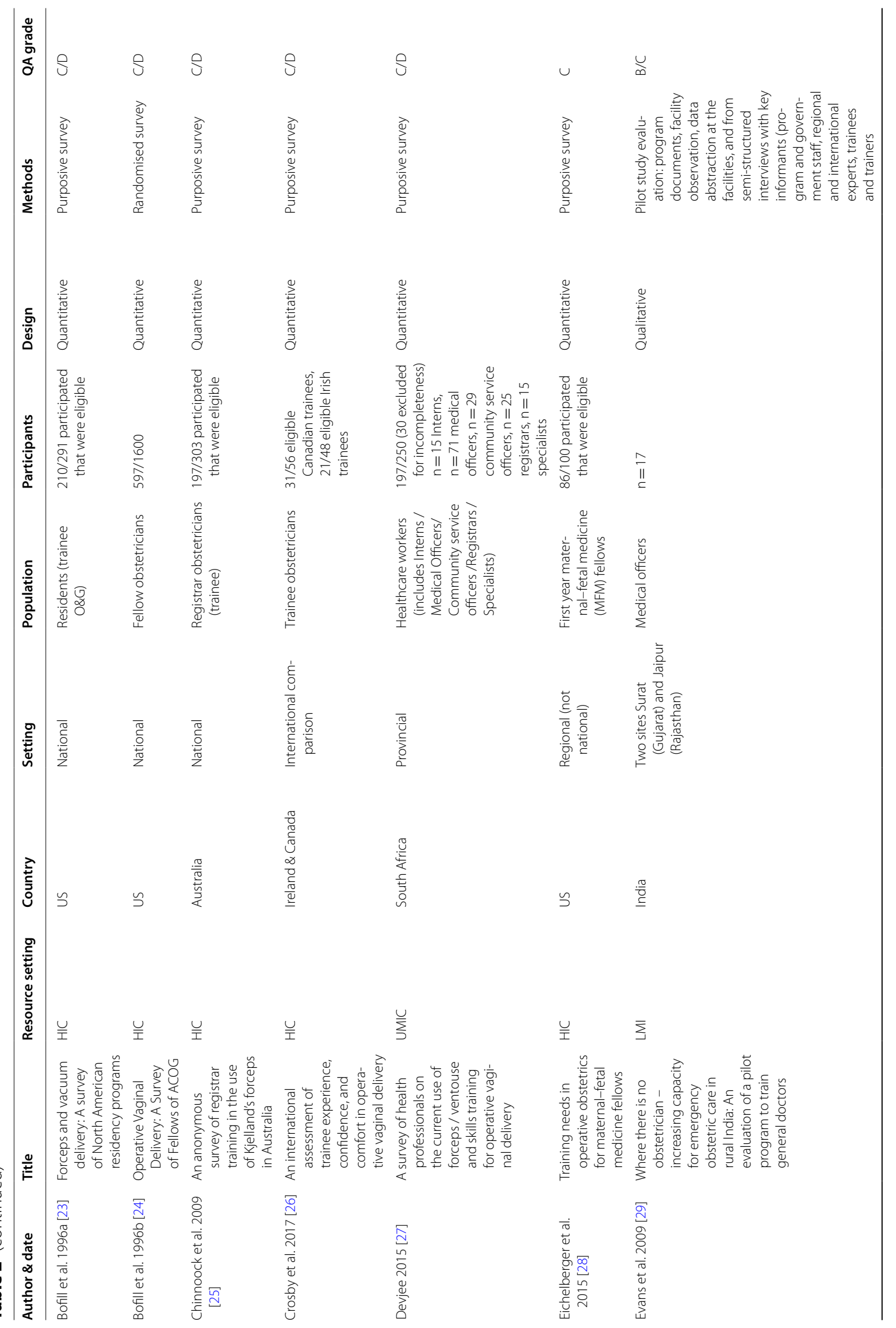




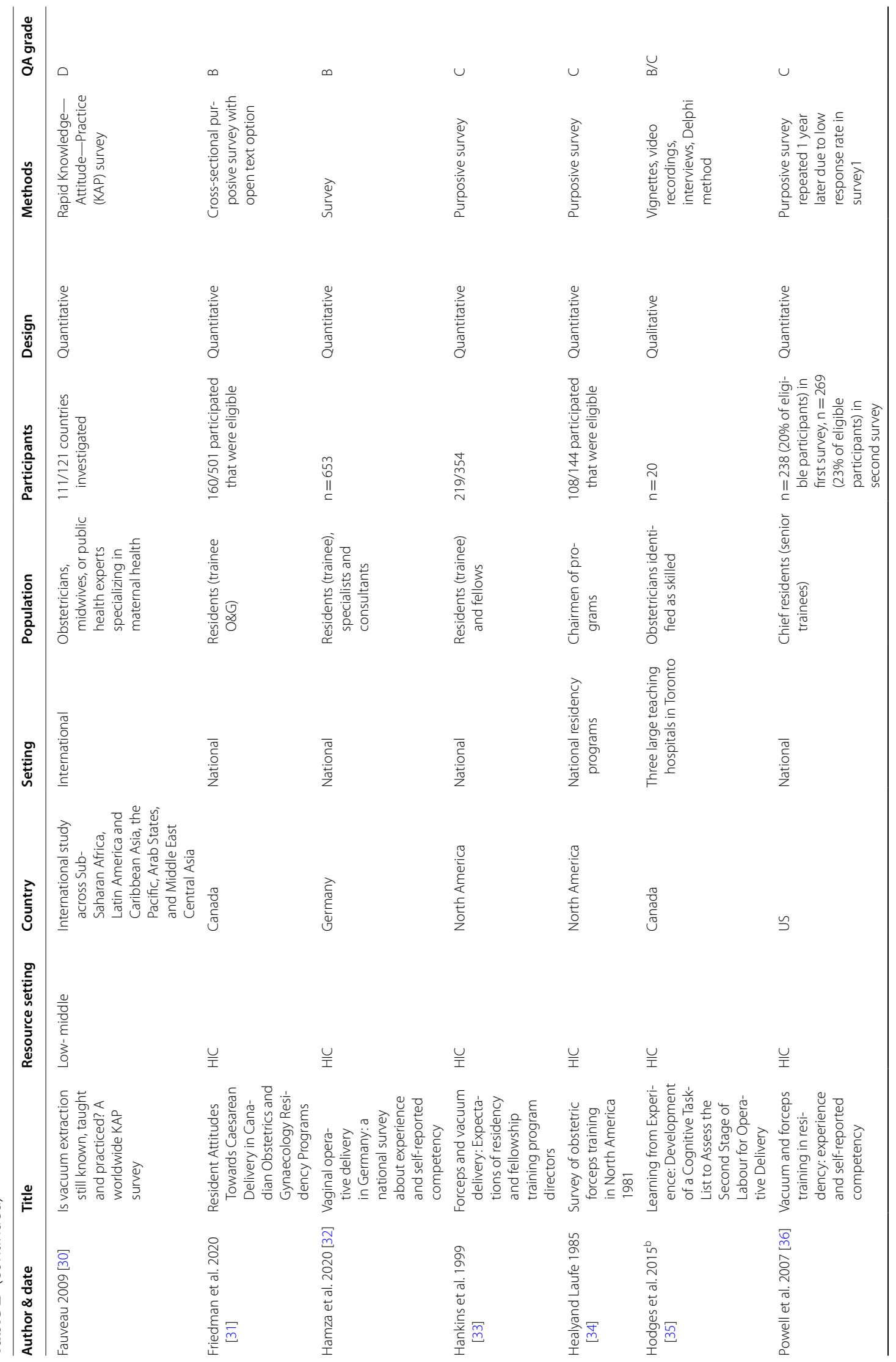




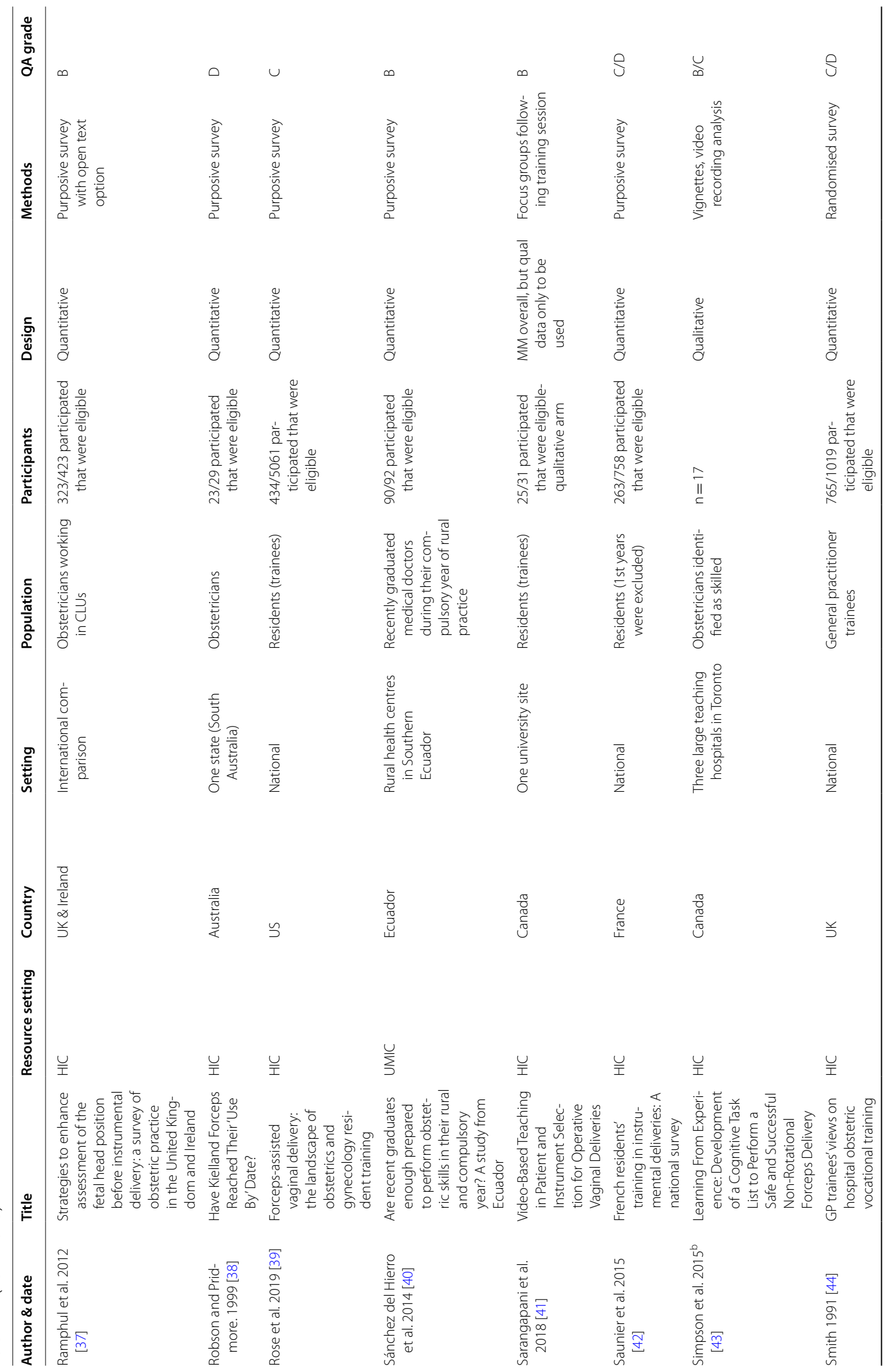




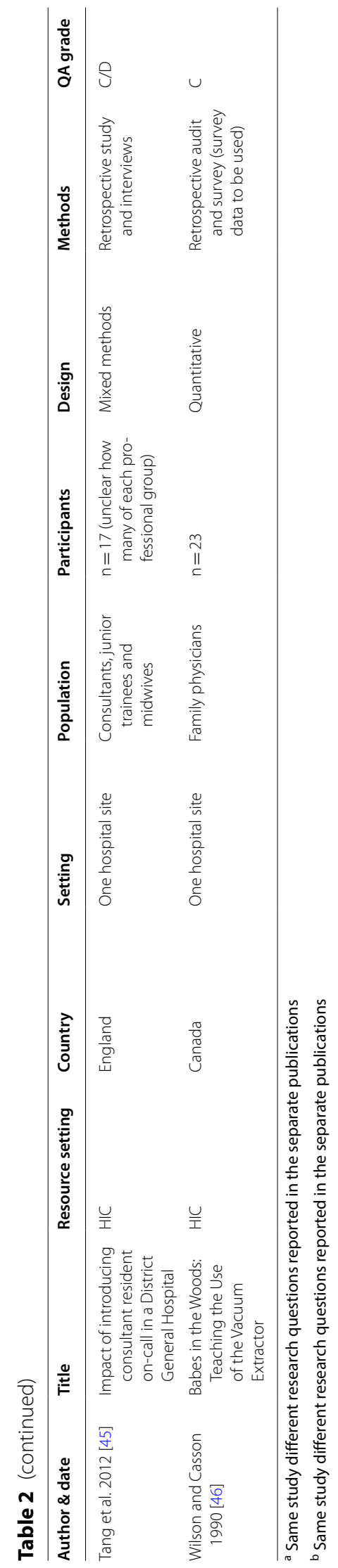




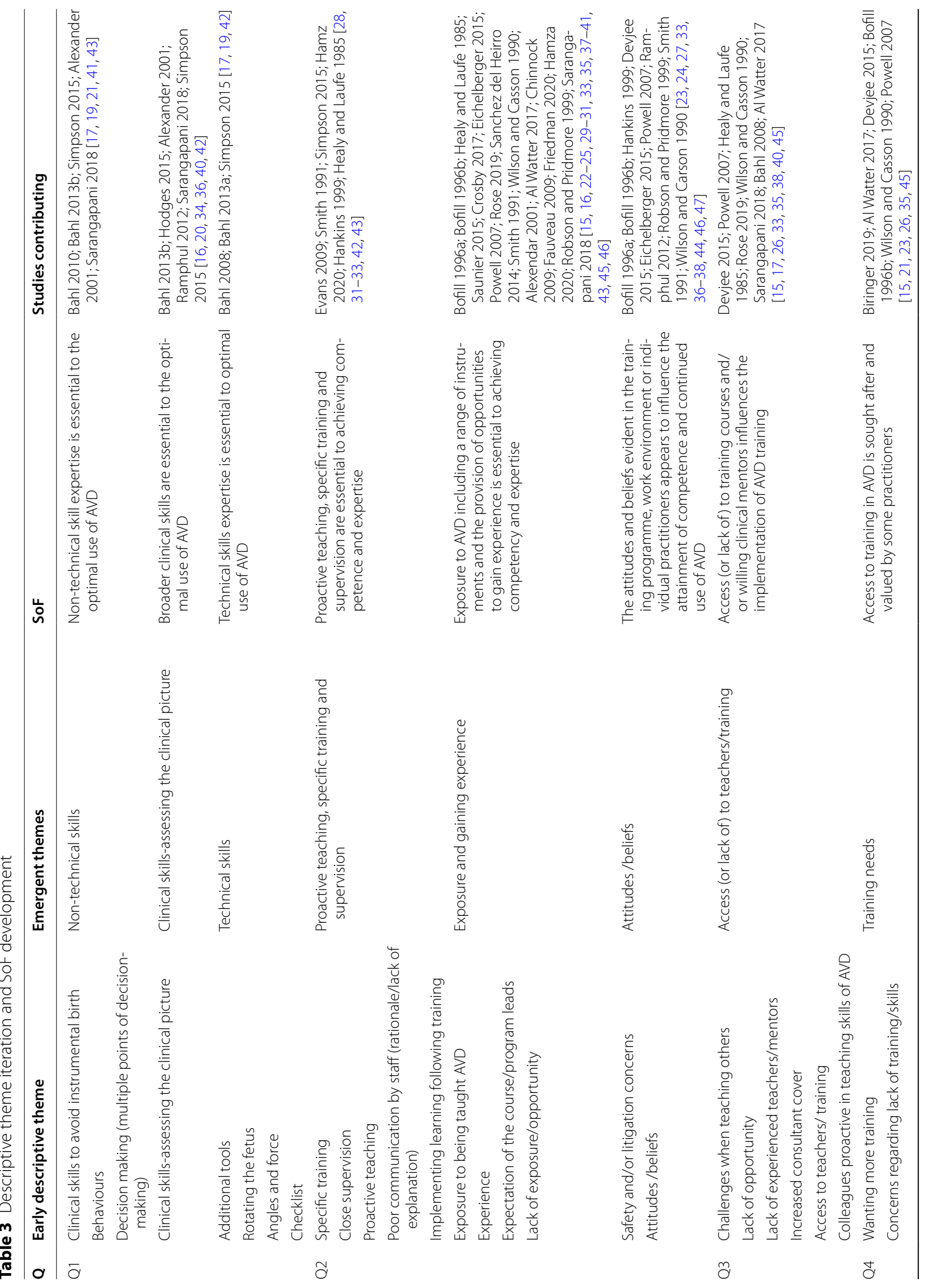




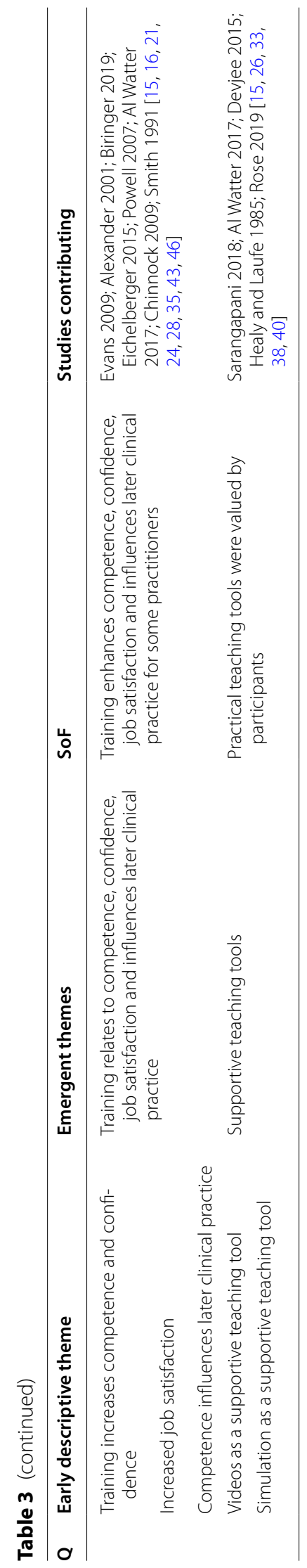




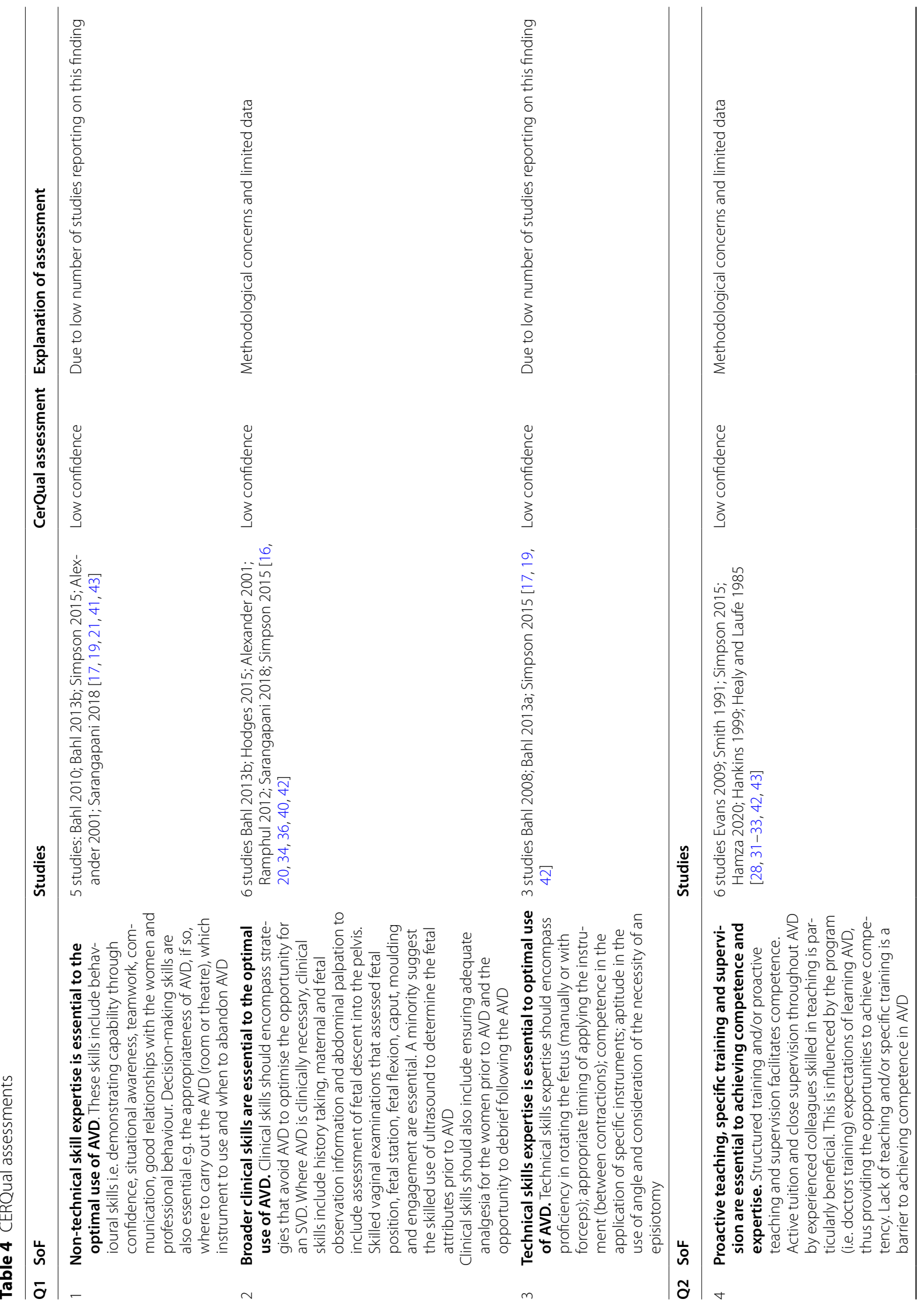




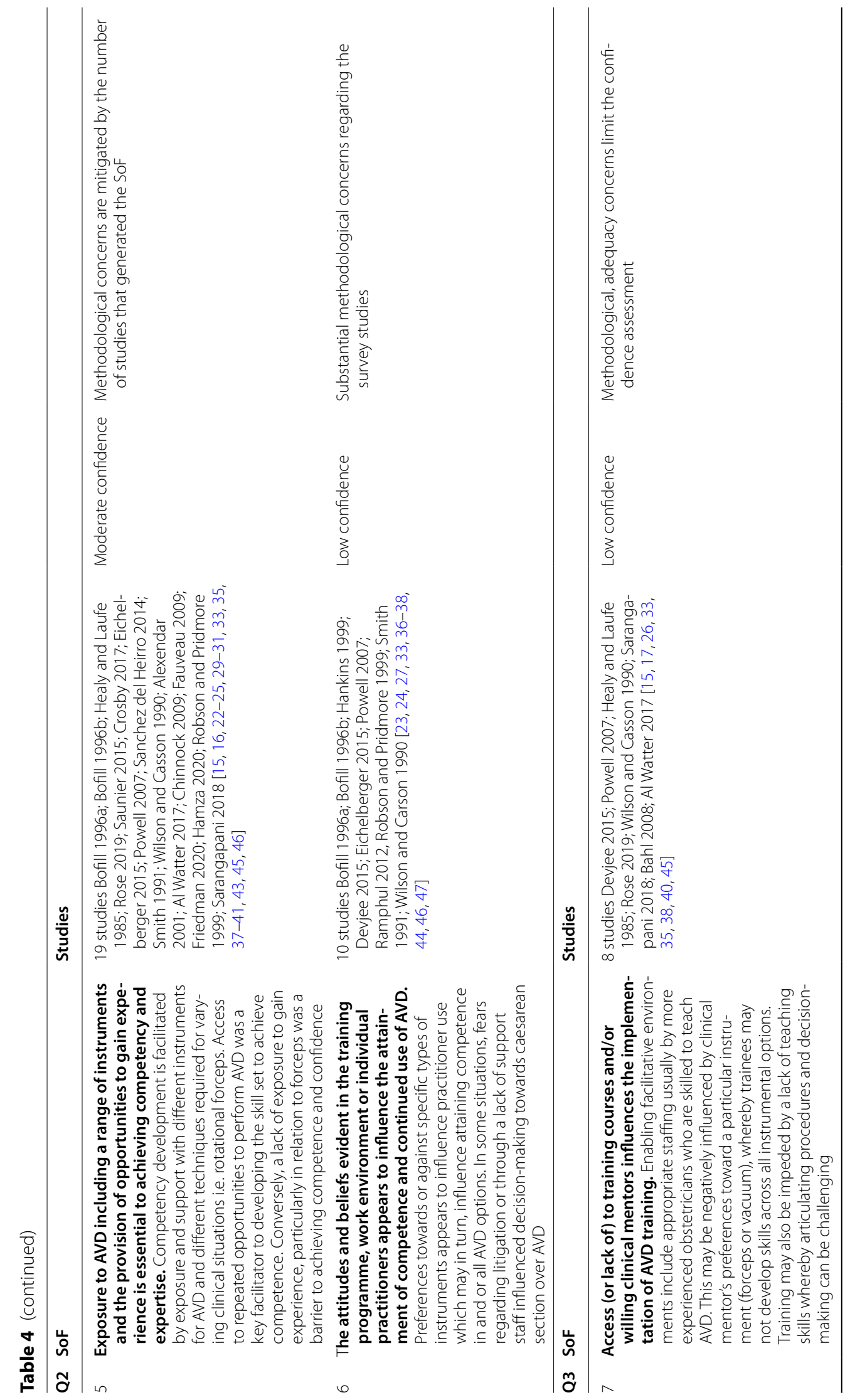




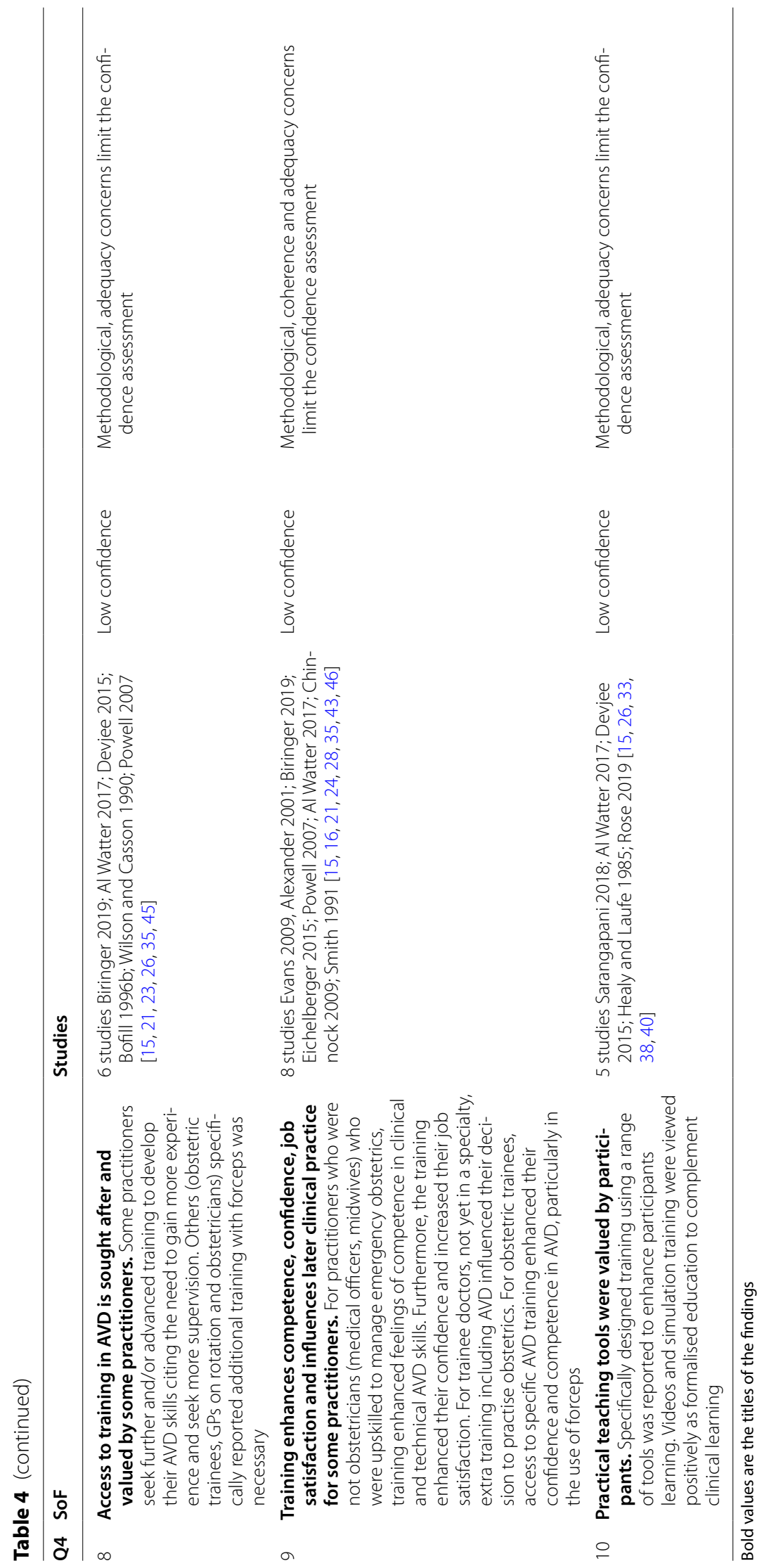


awareness, teamwork, communication, good relationships with the women, professional behaviour and decision-making. Bahl et al. [19] identified three essential behavioural elements; calmness, confidence/assertiveness and self-awareness, including self-knowledge of professional limitations [19]. The importance of decisionmaking skills were highlighted across the five studies [17, 19, 21, 41, 43]. While these are also essential for clinical practice in general, the studies emphasised the importance of key decision-making points for AVD specifically, including clinical skills that can be used to avoid instrumental birth [17, 19, 41]. For example, a midwife who had been trained to use the ventouse commented:

$\therefore$...the art...is in diagnosing the babies you don't attempt to do a ventouse on. OPs, OTs, brows, etc., high heads-diagnosis during VEs in labour p.167. [17]

Where AVD was deemed appropriate, other decisions were identified i.e. where to carry out the AVD (labour room or operating theatre) [21,41,43], which instrument to use [21] and when to abandon AVD in favour of caesarean section [19, 21, 43]. Such decision-making involved the weighing up of multiple and simultaneous factors. For example, the likelihood of success in a particular case influenced the decision of whether to perform the AVD in the labour room, or to recommend transfer to an operating theatre before attempting the procedure [21].

\section{Clinical skills}

Six studies [17, 21, 35, 37, 41, 43] reported on the broader clinical skills/assessment of the clinical picture required for optimal use of AVD. In the first instance, Bahl [21] captured specific clinical practices (as distinct from the decision-making skills noted above) from obstetricians and midwives deemed as experts, of techniques they used to encourage a spontaneous vaginal birth in a situation where there was a chance that this might be achieved safely, but with a view to moving rapidly to instrumental birth if necessary.

If she has been pushing for $1 \mathrm{~h}$ and the vertex is visible, one option is to continue pushing for another period of time to see if she can have a spontaneous vaginal delivery.......If the head was crowning but held back by the perineum, it will be an option to offer episiotomy.....Check if she has passed urine or whether it would be appropriate to catheterise and empty the bladder to allow delivery......If there is no concern regarding CTG and the contractions are inadequate, consider putting up syntocinon to augment the contractions p.337.' D5 [21]
Where other techniques had been tried, or where AVD was clearly the safest option, other clinical skills were highlighted across the six studies $[17,21,35,37$, 41, 43]. These included assessing the woman's history and current clinical picture and ensuring fetal/maternal signs of wellbeing before proceeding to AVD rather than an emergency surgical birth [17, 21,35]. Sarangapani et al. [41] emphasised their belief in the importance of abdominal palpation skills which they divided into three components:

(1) palpating the abdomen for a clinical assessment of fetal size; (2) palpating a central gap, typically a handbreadth between the xiphoid process and the fetal buttock, as an indication of good head descent into the pelvis; and (3) performing a bimanual examination, with one hand on the abdomen measuring the amount of fetal head (in fingerbreadths) above the pubic symphysis as an indication of fetal head descent p. 1165.' [41]

Additionally, practitioners' beliefs in the importance of skilled vaginal examinations was highlighted across the six studies [17, 21, 35, 37, 41, 43]. One study provided a detailed analysis relating to vaginal examinations: Ramphul et al. [37] surveyed 323 obstetricians (trainees and consultants) and found that between 98 and $99 \%$ of the surveyed obstetricians identified the following as benefits of undertaking skilled vaginal examinations; establishing fetal position, fetal station, the degree of cephalic caput and moulding of the fetal skull; and the degree of engagement of the presenting fetal part. While the survey found proportional differences between consultants and trainees, respondents of all grades agreed with the importance of assessing asynclitism of the presenting fetal part, flexion of the head, and estimated fetal size [37]. However, some obstetricians (18.7\%) and trainees (23.1\%) used ultrasound to aid diagnosis of the fetal head position if they had difficulty in determining fetal position digitally [37]. Simpson et al. [43] provided criteria regarding the vaginal examination to guide AVD decision-making i.e. the cervix must be fully dilated; membranes must be ruptured; and the presenting part must be at least at the level of the ischial spines [43].

Only three papers (two studies) referred to the importance of ensuring women had adequate analgesia $[21,35$, 43] prior to AVD, arguably an essential clinical skill. One recommended offering 'a debrief with parents, both at the time of delivery and the following day (ideally) p. 591' [43]. No studies mentioned the need to discuss the procedure with the woman, and to obtain authentic consent from her prior to proceeding. 


\section{Technical skills and expertise}

The technical skills required for optimal AVD were highlighted in three papers, two of which were based on the same dataset $[18,20,43]$. The studies noted the need for specific skills where the presentation was not directly occipito-anterior, including expertise in the positioning of the forceps blades for rotational (Kielland) forceps [18], and in manual rotation followed by the use of forceps for direct traction (non-rotational forceps delivery) [43]. More generally, these skills included the need for specific technical expertise in judging the timing of applying the instrument (between contractions); competence in the application of specific instruments; aptitude in the appropriate angle of traction; and consideration of the necessity, or not, of an episiotomy [18, 20, 43].

\section{What are the barriers and facilitators to achieving these levels of expertise and competence?}

Three SoF's were relevant to this question; proactive teaching, specific training and supervision (low confidence), exposure to opportunities to gain experience in AVD (moderate confidence), the attitudes and beliefs of mentors, training programs and/or localised clinical placements (low confidence).

\section{Proactive teaching, and specific training and supervision}

Six studies [29, 32-34, 43, 44] highlighted facilitatory factors. These were: proactive teaching, specific training, and targeted supervision to enable the development of competence in AVD. For example, structured and specific training provided to medical officers for emergency obstetric care in rural India was reported as highly beneficial [29], particularly for skills in undertaking AVD where the capacity to perform safe caesarean sections was limited. In a high income country (UK); GP trainees survey respondents [44] reported that the more teaching they had received the more relevant they thought obstetric training (including the performance of AVD) was to the provision of obstetric care in the community. In a national survey administered to all obstetricians in Germany [32], those actively tutored by their colleagues were significantly less likely to report incompetence when using forceps or vacuum extraction highlighting the benefits of proactive teaching and specific training.

Two surveys $[38,41]$ found barriers to gaining competencies in AVD. Sarangapani et al. [41] carried out a mixed-methods study with trainee obstetricians and found several challenges to their learning, including poor communication by mentors:

$\therefore$...II... find teaching on this topic tends to happen on call and it is kind of rushed. They don't go through a super detailed rationale because there isn't always time and some people have developed a gestalt of doing things, and they can't always elucidate why they are doing it p. 1166.' [41]

Additional barriers related to lack of opportunities. Preferences of existing staff, and the norms of particular hospitals, negatively influenced clinical learning opportunities (e.g. 'instrument selection is largely institutionally dependent' [41]). Lack of theoretical or formalised education was also noted [41]. This was echoed by another survey [38] of 23 trainee obstetricians, where virtually all respondents expressed concern about a lack of training opportunities with Kielland forceps.

A survey of obstetric residency program directors [33] inferred that program expectations influenced the opportunities available to the trainees to develop competency in AVD, both negatively and positively:

All programs expected their graduates to be proficient in outlet deliveries... 97\% of residency and $100 \%$ of fellowship directors expected proficiency; for vacuum, 92\% expected proficiency in both types of training programs. In contrast, only $38 \%$ of residency and 48\% of fellowship program directors expected proficiency with mid [cavity]-forceps, while 69 and $73 \%$ expected proficiency with mid-vacuum p.26.' [33]

\section{Exposure to AVD including a range of instruments and the provision of opportunities to gain experience}

19 studies illustrated facilitators and/or barriers related to the degree to which trainees had exposure to AVD within their clinical practice areas, and, therefore, opportunities to gain experience [16, 17, 23-26, 30-32, 34, 36, $38-42,44,46,47]$. Issues related to exposure (or lack of) was particularly highlighted regarding the rate at which specific instruments were used locally $[16,17,23-26,30$ $32,34,36,38-42,44,46,47]$. Inter-regional differences were found in several surveys [23, 24, 26, 34, 36, 39, 40, $42,46]$ highlighting that the localised context influences the use and teaching of instruments. For example,

'There was however a significant difference in number of [forceps assisted vaginal deliveries] FAVDs performed by region $(p<0.0001)$. Residents from the Midwest completed the most FAVDs compared to any other region, with 9\% having completed $>30$ FAVDs and 27\% having completed 11-30 FAVDs p. 2. [39] 


\section{The attitudes and beliefs influence the attainment of competence and continued use of AVD}

Some studies reported the cessation of teaching mid-pelvic operative vaginal deliveries citing safety and litigation concerns [23, 33]. Such fears were reflected in another study whereby some trainees reported they would not use any forceps, at all, in their clinical practice [38] also due to fears of safety and/or litigation. This concern was echoed by experienced obstetricians in a survey carried out in South Africa [27], who reported that only twenty-one $(10 \%)$ of the participants continued to do operative vaginal deliveries (OVD) (approximately 1-2 every 3-6 months) following their training. The authors hypothesised that the majority of survey participants would resort to caesarean section because of the fear of litigation and the lack of skilled personnel in attendance in OVD [27].

Conversely, related to the vacuum extractor, a survey in Canada [46] showed how exposure to the successful use of instrumental birth can change attitudes and beliefs over time:

\section{'If you administered your vacuum extractor ques- tionnaire to me now I would give much more enthu- siastic responses about the use of the vacuum. The midwives here do the normal deliveries, and the doctors are called for complications. We only have a small hand-held vacuum extractor but it has seen me through many difficult deliveries p. 1722.' [trainee in Canada, now working in Ethiopia] [46]}

\section{What are the barriers and facilitators to implementation of appropriate training?}

One SoF was relevant to the research question; access (or lack of) to training courses and/or willing clinical mentors influences the implementation of AVD training (low confidence).

\section{Access (or lack of) to training courses and/or willing clinical mentors influences the implementation of AVD training}

Eight studies [16, 18, 27, 34, 36, 39, 41, 46] generated insights regarding the barriers/facilitators to the implementation of appropriate AVD training. In South Africa, a survey found of 197 participants, 84\% had learned AVD from 'essential steps in the management of obstetrics emergencies' (ESMOE) training modules indicating good uptake when training was available [27]. Other studies reported that willing clinical mentors who were proactive in their teaching of AVD positively influenced appropriate training $[16,18,34,36,39,41,46]$. Conversely, two studies illustrated the negative influence of poor teaching, as a result of which the articulation of AVD skills was reported as challenging and some participants reported conflicting messages between mentors [18, 41]. In another survey of 81 trainees, (35\%) were not even sure if training on the use of AVD was provided in their units, or not [16].

\section{What are the views, opinions, perspectives and experiences of maternity care practitioners on training for use of AVD?}

The final three review findings suggested that access to training sought after and is valued (low confidence); it enhances competence, confidence, job satisfaction and influences later clinical practice for some practitioners (low confidence); practical teaching tools were value (low confidence).

\section{Access to good quality training in AVD is sought after and valued by some practitioners}

Six studies [16, 22, 24, 27, 36, 46] found that participants sought further and/or advanced training to further develop their AVD skills or to gain more experience. For example, a survey in Canada [22] with family physicians who underwent an advanced fellowship, reported 69\% of 87 respondents stated that they took the fellowship because they wanted more experience, and the same proportion did not feel ready to practise obstetrics (in general that included AVD) without supervision. In another survey [16], of 87 obstetric trainees, 'the majority felt that they needed training in using Kielland's forceps (71/87, $81.6 \%)$ '. These participants identified further training needs despite being on an obstetric trainee programme.

\section{Good quality training enhances competence, confidence, job satisfaction and influences later clinical practice for some practitioners}

Eight studies [16, 17, 22, 25, 29, 36, 44, 47] identified positive experiences of training. For practitioners who were not obstetricians (medical officers, midwives) who were trained to manage emergency obstetrics, training enhanced feelings of competence and confidence in clinical and technical AVD skills. Furthermore, the training enhanced participants' confidence and increased their job satisfaction. A mixed methods study of midwives who had undertaken ventouse training [17] found 15/18 participants felt that becoming a midwifery ventousepractitioner (MVP) had positively affected their overall midwifery practice, and enhanced confidence in abdominal palpation and vaginal examinations as well their ability to 'handle' a prolonged labour. One respondent said [17]- 'I am much more likely to try everything to obtain a normal delivery... (Midwife 14 p. 168).'

Likewise, family physicians who embarked on an advanced fellowship were much more likely to intend to practice obstetrics following the training [22]: 
'Eighty-two percent of participants indicated that the ability to access extra training influenced their decision to practise obstetrics. They cited that the fellowship made them more confident and more comfortable with intrapartum care. When asked if the fellowship was useful to their current practice, $75 \%$ rated it a 6 or 7 (on a 7-point scale where 7 was "essential"; mean rating 5.9); 93\% said that they would choose to complete the extra training again p.534: [22]

\section{Practical teaching tools were valued by participants}

Five studies reported the value of practical and specifically designed training that incorporated different teaching modalities [16, 27, 34, 39, 41]. Videos and simulation training were viewed positively as an adjunct to clinical learning [27, 34, 41]. However, the authors from a study that introduced video based learning [41] emphasised that alternate teaching methods that 'act as complementary tools to clinical teaching, but there was agreement that they should not replace hands-on clinical teaching ( $p$. 1167).'

\section{Discussion}

The aim of this review was to improve understanding of the characteristics of competency and expertise in AVD, and to generate insights regarding the barriers and potential facilitating factors relating to expertise, training, implementation of and competencies in AVD. We identified 27 studies of health professionals' views of training and competencies for AVD, mostly in high income countries.

We found that AVD competency comprises three inter-related components; non-technical skills, broader obstetric clinical skills and specific technical skills associated with particular instrument use. Practitioners felt that they needed additional training and exposure to AVD in practice to gain skills and confidence in this field, even after they had officially qualified (including those who had undertaken specialist obstetric training). Teaching aids such as simulation and video teaching tools were viewed as a valuable complement to clinical mentorship. However, the attitudes and behaviours of their colleagues and mentors, and the norms of their training and employing institution, were critical in determining if an individual practitioner would consider using AVD in routine practice, or not. This included the degree to which the fear of litigation in the employing organisation, and/or among peers and senior staff, influenced rapid recourse to caesarean section in preference to any kind of vaginal birth in three studies [23, 27,33]. Good quality clinical mentorship or supervision was also particularly influential for trainees to gain competence, confidence and expertise in all instrumental births, or conversely was a negatively influencing factor.

Only three relevant qualitative studies were identified in our extensive searches. The majority of studies (23 out of 27 were from high-income countries). These limitations are reflected in our CERQual assessments, which were low for all except one summary of findings statement. This review also includes some older studies that may not be relevant for current practice. For instance, some of the studies refer to UK general practitioners undertaking AVD, but this cadre of doctors no longer routinely attends births in the UK. An important strength of the review is that it has located all studies in all languages that have been published to date, and it includes survey data. Our searches also found 28 studies that were either pre/post-test AVD training intervention quasi-experimental, RCT training intervention studies, or cross-sectional studies that examined maternal/neonatal outcomes following training [47-73]. Those studies did not meet our criteria for inclusion, but they do warrant further investigation in future reviews to determine the attributes, effectiveness and efficacy of good training that meet the needs of practitioners, and of service users.

Findings from our previous review [6] highlighted for both parents, the distress of unexpected interventions associated with AVD (including episiotomy, need for unplanned pain relief, such as epidural analgesia, and concern for possible iatrogenic harm to the baby of using instruments) may be mitigated by how health professionals communicate, both at the time of decision-making, and during the process. In the present review only three papers (two studies) referred to ensuring women had adequate analgesia and one discussed offering parents a debrief following AVD [18, 34, 42]. Although this knowledge may be implicit or assumed information, The Royal College of Obstetricians and Gynaecologists (RCOG) [48], the Royal Australian and New Zealand College of Obstetricians and Gynaecologists (RANZCOG) [49], and the Society of Obstetricians and Gynaecologists of Canada (SOGC) [50] guidelines for instrumental vaginal birth all highlight the importance of adequate postnatal care and counselling.

The 2020 update of the American College of Obstetricians and Gynaecologists (ACOG) [51] guidance on operative vaginal birth also include lists of prerequisites for AVD. Several of the studies we included in our review did generate checklists based on their research findings to establish the components: of a skilled low-cavity nonrotational vacuum delivery [17], of a skilled rotational forceps delivery [19], non-technical skills, cognitive or decision-making aids for instrumental births $[18,20$, 34, 42]. These tools do not appear to have been formally 
evaluated in practice. Preparing clinicians and maintaining the proficiency in the recognition and management of events that are relatively rare such as emergency obstetrics is a challenge, including AVD and caesarean section [52-56]. Evidence on the effectiveness of the multiple methods in use (e.g. classes, simulation-based training methods, rehearsals, drills, interactive training) is suboptimal. Although, multidisciplinary training has been recognized as essential including clinical and non-clinical skills [57], identification of the most useful combination of methods remains uncertain and warrants future studies to rigorously assess effectiveness. This is particularly important in low- and middle-income countries where healthcare providers cannot rely on strong health systems, referral structure or appropriate supplies flow. AVD is one of the seven basic services as prerequisites for emergency obstetric care as defined by the WHO. The main reasons cited for the low rates in LMICs are known to include lack of skilled healthcare workers and lack of resources with the establishment of training programs for all skilled birth attendants a priority [58].

AVD is not without risks. In this review fear of bad outcomes and litigation were concerns reported by some clinicians. These factors coupled with suboptimal training and thus low levels of skills underpin the deprioritization of AVD in favour of caesarean section [58]. Low- and middle-income countries are most affected by this trend and the use of AVD is almost non-existent in these settings [3]. However, caesarean section is not without risks either and it is precisely in these countries and in resource constrained conditions where appropriate and skilled use of AVD could have a more significant impact by optimizing the use of caesarean section and improving perinatal outcomes [1]. Effective training programmes need to be revitalized in order to foster feasible alternative solutions for emergency obstetric care. This also includes close supervision by experienced consultants, as highlighted in a recent study [59]. In addition, research is on-going on new devices such as the Odon device, with a potentially safer profile and easier to use for all cadres of birth attendants that could possibly expand the options to expedite birth and improve maternal and perinatal outcomes when certain complications arise during labour [60-62].

\section{Strengths and limitations}

The strengths of this study are that a comprehensive and rigorous search strategy was undertaken, including reviewing papers in other languages. While an evidence synthesis is an interpretative process, the risk of over or under interpretation of the data was minimized through author reflexivity to ensure that personal beliefs and values did not obscure important data within the included studies, and through rigor in study selection and analysis. However, there are some limitations; we were unable to undertake the planned meta-thematic synthesis due to the few qualitative studies found, and the low quantity and/or quality of the data presented in them. Due to this factor, we were also not able to carry out the pre-planned convergence.

\section{Conclusion}

Most AVD techniques can be used safely in very low resource environments, by single practitioners. Most women prefer to give birth vaginally. Skilled, respectful AVD can be a safe, acceptable, and low-cost solution when birth needs to be expediated. Fear of bad outcomes and litigation are factors likely to be compounded when professional training is inadequate to ensure confidence and competence in clinicians' skills in this area, or when local colleagues and seniors, or organisational norms, deprioritise AVD in favour of caesarean section. Our findings suggest that both pre- and post-registration training for maternity care practitioners needs to include the development of positive attitudes. Access to specific AVD training, using a combination of teaching methods, complements, but does not replace, close clinical mentorship from experts who are positive about AVD, and opportunities to practice emerging AVD skills with supportive supervision. Further research is required to ascertain effective modalities for wider training, education, and supportive supervision for optimal AVD use.

\section{Abbreviations}

AVD: Assisted vaginal delivery.

\section{Supplementary Information}

The online version contains supplementary material available at https://doi. org/10.1186/s12978-021-01146-3.

Additional file 1: Table S1. Example search-MEDLINE.

Additional file 2. QA.

Additional file 3. Data extraction.

Additional file 4. Excluded studies.

Acknowledgements

We are very grateful for the search development support provided by Cath Harris, Information Specialist at the University of Central Lancashire and Tomas Allen, Librarian at WHO.

\section{Authors' contributions}

CF-search, study selection, data extraction, data synthesis, writing the manuscript. NC-conception, study selection, data extraction, revising the manuscript. APB- conception, study selection, revising the manuscript. AWrevising the manuscript. SD- conception, study selection, data extraction, data synthesis, revising the manuscript. CK- conception, study selection, data extraction, data synthesis, revising the manuscript. All authors read and approved the final manuscript. 


\section{Funding}

This study was funded by the UNDP/UNFPA/UNICEF/WHO/World Bank Special Programme of Research, Development and Research Training in Human Reproduction (HRP), Department of Sexual and Reproductive Health and Research at the World Health Organization.

\section{Availability of data and materials}

The search strategy, screening and data extraction tables have been supplied as Additional files within this submission.

\section{Declarations}

\section{Ethics approval and consent to participate}

Not applicable.

\section{Consent for publication}

Not applicable.

\section{Competing interests}

The authors declare no competing interests.

\section{Author details}

${ }^{1}$ School of Community Health and Midwifery, University of Central Lancashire, Preston PR1 2HE, UK. ² Department of Reproductive Health and Research, World Health Organisation, 1211 Geneva 27, Switzerland. ${ }^{3}$ Sanyu Research Unit, Liverpool Women's Hospital Women and Children's Health, University of Liverpool, Liverpool L87SS, UK.

Received: 10 September 2020 Accepted: 26 April 2021 Published online: 05 May 2021

\section{References}

1. Nolens B, Capelle M, van Roosmalen J, Mola G, Byamugisha J, Lule J, Faye $A$, van den Akker T. Use of assisted vaginal birth to reduce unnecessary caesarean sections and improve maternal and perinatal outcomes. Lancet Glob Health. 2019;7(4):e408-9.

2. World Health Organization: WHO recommendations non-clinical interventions to reduce unnecessary caesarean sections. 2018. https://apps. who.int/iris/bitstream/handle/10665/275377/9789241550338-eng.pdf? $\mathrm{ua}=1$.

3. Bailey PE, van Roosmalen J, Mola G, Evans C, de Bernis L, Dao B. Assisted vaginal delivery in low and middle income countries: an overview. BJOG. 2017;124(9):1335-44.

4. Betrán AP, Temmerman M, Kingdon C, Mohiddin A, Opiyo N, Torloni MR, Zhang J, Musana O, Wanyonyi SZ, Gülmezoglu AM, Downe S. Interventions to reduce unnecessary caesarean sections in healthy women and babies. Lancet. 2018;392(10155):1358-68.

5. Pattinson RC, Vannevel V, Barnard D, Baloyi S, Gebhardt GS, Le Roux K, Moran N, Moodley J. Failure to perform assisted deliveries is resulting in an increased neonatal and maternal morbidity and mortality: an expert opinion. S Afr Med J. 2018:108(2):75-8.

6. Crossland N, Kingdon C, Balaam M, Betrán AP, Downe S. Women's, partners' and healthcare providers' views and experiences of assisted vaginal birth: a systematic mixed methods review. Reprod Health. 2020;17:1.

7. Kingdon C, Downe S, Crossland N, Feeley C, Balaam MC, Betran AP. Training in assisted vaginal delivery (AVD) to facilitate complicated deliveries and reduce unnecessary caesarean sections: a systematic review. PROSPERO 2020 CRD42020178525. https://www.crd.york.ac.uk/prospero/displ ay_record.php?ID=CRD42020178525

8. Noyes J, Booth A, Moore G, Flemming K, Tunçalp Ö, Shakibazadeh E. Synthesising quantitative and qualitative evidence to inform guidelines on complex interventions: clarifying the purposes, designs and outlining some methods. BMJ Glob Health. 2019;4(Suppl 1):e000893.

9. Cochrane. EPOC resources for review authors. 2020. http://epoc.coch ane.org/epoc-specific-resources-review-authors.

10. Covidence Covidence.org https://www. covidence.org/home.

11. BMJ. Critical appraisal checklist for a questionnaire study. 2020. https:// www.bmj.com/content/suppl/2004/05/27/328.7451.1312.DC1
12. Walsh $D$, Downe S. Appraising the quality of qualitative research. Midwifery. 2006;22:108-19.

13. Hong QN, Fàbregues S, Bartlett G, Boardman F, Cargo M, Dagenais P, Gagnon M, Griffiths F, Nicolau B, O'Cathain A, Rousseau M, Vedel I, Pluye P. The Mixed Methods Appraisal Tool (MMAT) version 2018 for information professionals and researchers. Educ Inf. 2018;34(4):285-91.

14. Downe S, Walsh D, Simpson L, Steen M. Template for metasynthesis. 2009, contact SDowne@uclan.ac.uk

15. Lewin S, Glenton C, Munthe-Kaas H, Carlsen B, Colvin C, Gülmezoglu $\mathrm{M}$, et al. Using qualitative evidence in decision making for health and social interventions: an approach to assess confidence in findings from qualitative evidence syntheses (GRADE-CERQual). Plos Med. 2015;12(10):e1001895.

16. Al Wattar BH, Mahmud A, Janjua A, Parry-Smith W, Ismail KM. Training on Kielland's forceps: a survey of trainees' opinions. J Obstet Gynaecol. 2017:37(3):280-3.

17. Alexander J, Anderson T, Cunningham S. An evaluation by focus group and survey of a course for Midwifery Ventouse Practitioners. Midwifery. 2002;18(2):165-72.

18. Bahl R, Murphy DJ, Strachan B. Qualitative analysis by interviews and video recordings to establish the components of a skilled low-cavity nonrotational vacuum delivery. BJOG. 2009;116(2):319-26.

19. Bahl R, Murphy DJ, Strachan B. Non-technical skills for obstetricians conducting forceps and vacuum deliveries: qualitative analysis by interviews and video recordings. Eur J Obstet Gynecol Reprod Biol. 2010;150(2):147-51.

20. Bahl R, Murphy DJ, Strachan B. Qualitative analysis by interviews and video recordings to establish the components of a skilled rotational forceps delivery. Eur J Obstet Gynecol Reprod Biol. 2013;170(2):341-7.

21. Bahl R, Murphy DJ, Strachan B. Decision-making in operative vaginal delivery: when to intervene, where to deliver and which instrument to use? Qualitative analysis of expert clinical practice. Eur J Obstet Gynecol Reprod Biol. 2013;170(2):333-40.

22. Biringer A, Abells D, Boro J, Permaul JA, Sinha S, Graves L. Enhanced skills training in family medicine maternity care: cross-sectional study of graduates' experiences. Can Fam Physician. 2019;65(12):e531-7.

23. Bofill JA, Rust OA, Perry KGJ, Roberts WE, Martin RW, Morrison JC. Forceps and vacuum delivery: a survey of North American residency programs. Obstet Gynecol. 1996;88(4):622-5

24. Bofill JA, Rust OA, Perry KG, Roberts WE, Martin RW, Morrison JC. Operative vaginal delivery: a survey of fellows of ACOG. Obstet Gynecol. 1996:88(6):1007-10.

25. Chinnock $M$, Robson S. An anonymous survey of registrar training in the use of Kjelland's forceps in Australia. Aust N Z J Obstet Gynaecol. 2009:49(5):515-6.

26. Crosby DA, Sarangapani A, Simpson A, Windrim R, Satkunaratnam A, Higgins MF. An international assessment of trainee experience, confidence, and comfort in operative vaginal delivery. Ir J Med Sci. 2017:186(3):715-21.

27. Devjee J. A survey of health professionals on the current use of forceps/ ventouse and skills training for operative vaginal delivery. Obstetrics Gynaecol Forum. 2015;25(3):37-9.

28. Eichelberger KY, Bengtson AM, Tolleson-Rinehart S, Menard MK. Training needs in operative obstetrics for maternal-fetal medicine fellows. J Mater Fetal Neonatal Med. 2015:28(12):1467-70.

29. Evans CL: Where there is no obstetrician: Increasing capacity for Emergency Obstetric Care in rural India A study of a pilot program to train MBBS doctors and its adoption by the government. ProQuest Inform Learning. 2009.

30. Fauveau V. Is vacuum extraction still known, taught and practiced? A worldwide KAP survey. Int J Gynaecol Obstetrics. 2006;94(2):185-9.

31. Friedman CL, Ahmed RJ, Hutton EK, Darling EK. Resident attitudes towards caesarean delivery in Canadian obstetrics and gynaecology residency programs. J Obstetrics Gynaecol Canada. 2020:42(1):16-24.

32. Hamza A, Lavin JP, Radosa JC, Abou-Dakn M, Peitz I, Gerlinger C, MeybergSolomayer G, Ströder R, Juhasz-Böss I, Solomayer E-, Takacs FZ. Vaginal operative delivery in Germany: a national survey about experience and self-reported competency. J Mater Fetal Neonatal Med 2020, 0(0):1-7.

33. Hankins GD, Uckan E, Rowe TF, Collier S. Forceps and vacuum delivery: expectations of residency and fellowship training program directors. Am J Perinatol. 1999:16(1):23-8. 
34. Healy DL, Laufe LE. Survey of obstetric forceps training in North America in 1981. Obstet Gynecol. 1985;151(1):54-8.

35. Hodges R, Simpson A, Gurau D, Secter M, Mocarski E, Pittini R, Snelgrove J, Windrim R, Higgins M. Learning from experience: development of a cognitive task-list to assess the second stage of labour for operative delivery. J Obstet Gynaecol Can. 2015;37(4):354-61.

36. Powell J, Gilo N, Foote M, Gil K, Lavin JP. Vacuum and forceps training in residency: experience and self-reported competency. J Perinatol. 2007:27(6):343-6.

37. Ramphul M, O'Brien Y, Murphy DJ, Ramphul M, O'Brien Y, Murphy DJ. Strategies to enhance assessment of the fetal head position before instrumental delivery: a survey of obstetric practice in the United Kingdom and Ireland. Eur J Obstetrics Gynecol Reprod Biol. 2012;165(2):181-8.

38. Robson S, Pridmore B. Have Kielland forceps reached their "use by" date? Aust N Z J Obstet Gynaecol. 1999;39(3):301-4.

39. Rose K, Kwan L, Pluym ID, Zhang H, Han CS, Afshar Y. Forceps-assisted vaginal delivery: the landscape of obstetrics and gynecology resident training. J Mater Fetal Neonatal Med. 2019. https://doi.org/10.1080/14767 058.2019.

40. Sánchez Del Hierro G, Remmen R, Verhoeven V, Van Royen P, Hendrickx K. Are recent graduates enough prepared to perform obstetric skills in their rural and compulsory year? A study from Ecuador. BMJ Open. 2014;4(7):e005759.

41. Sarangapani A, Simpson AN, Snelgrove J, Higgins M, Windrim R, Satkunaratnam A. Video-based teaching in patient and instrument selection for operative vaginal deliveries. J Obstetrics Gynaecol Canada. 2018:40(9):1162-1169.e3.

42. Saunier C, Raimond E, Dupont A, Pelissier A, Bonneau S, Gabriel R, Graesslin O. French residents' training in instrumental deliveries: a national survey. J Gynecol Obstet Biol Reprod. 2016;45(9):1186-93.

43. Simpson AN, Gurau D, Secter M, Mocarski E, Pittini R, Snelgrove J, Hodges R, Windrim R, Higgins M. Learning from experience: development of a cognitive task list to perform a safe and successful non-rotational forceps delivery. J Obstetrics Gynaecol Canada. 2015;37(7):589-97.

44. Smith LF. GP trainees' views on hospital obstetric vocational training. BMJ (Clin Res Ed). 1991;303(6815):1447-50.

45. Tang JW, Dwyer JP, Rajesh U, Tang JWY, Dwyer JP, Rajesh U. Impact of introducing consultant resident on-call in a district general hospital. J Obstet Gynaecol. 2012;32(8):736-9.

46. Wilson CR, Casson RI. Babes in the woods: teaching the use of the vacuum extractor. Can Fam Physician. 1990;36:1720-4.

47. Eichelberger K, Tolleson-Rinehart S, Bentson A, Menard K. Training needs in operative obstetrics among first year maternal-fetal medicine fellows. Obstet Gynecol. 2013;208(1):S232.
48. Murphy DJ, Strachan BK, Bahl R. On behalf of the royal college of obstetricians gynaecologists: assisted vaginal birth. BJOG. 2020;127:e70-112.

49. RANZCOG: Instrumental vaginal birth. 2020; 1-26.

50. Cargill M, Mackinnon C. REAFFIRMED SOGC CLINICAL PRACTICE GUIDELINE|: No 148-guidelines for operative vaginal birth. J Obstetrics Gynaecol Canada. 2018;40(2):E74-80.

51. ACOG. ACOG.org, 2020. https://www.acog.org/clinical/clinical-guidance/ practice-bulletin/articles/2020/04/operative-vaginal-birth.

52. Merriel A, Ficquet J, Branard K, et al. The effects of interactive training of healthcare providers on the management of life-threatening emergencies in hospital. Cochrane Database Syst Rev. 2019;9:CD012177.

53. Hotton EJ, Renwick S, Barnard K, et al. Exploring standardisation, monitoring and training of medical devices in assisted vaginal birth studies: protocol for a systematic review. BMJ Open. 2019;9:e028300.

54. Draycott TK, Collins KJ, Crofts JF, et al. Myths and realities of training in obstetric emergencies. Best Pract Res Clin Obstet Gynaecol. 2015;29(8):1067-76.

55. Draycott T. Not all training for obstetric emergencies is equal, or effective. BJOG. 2017;124(4):651.

56. Sultana N, Betrán AP, Khan KS, Sobhy S. imulation-based teaching and models for caesarean sections: a systematic review to evaluate the tools for the 'See One, Practice Many, Do One' slogan. Curr Opin Obstet Gynecology. 2020;32:305.

57. PROMPT. Prompt.org. https://www.promptmaternity.org/Default.aspx.

58. Vanneval V, Swanepoel C, Pattinson RC. Global perspectives on operative vaginal deliveries. Best Pract Res Clin Obstet Gynaecol. 2019;56:107-13.

59. Ashraf $Z$, Crone L, Higgins MF. Factors affecting confidence and competence of doctors in performing operative vaginal births: a qualitative study. Eur J Obstet Gynecol Reprod Biol. 2021;258:348-52.

60. Schvartzman JA, Krupitzki H, Merialdi M, et al. Odon device for instrumental vaginal deliveries: results of a medical device pilot clinical study. Reprod Health. 2018;1:45.

61. O'Brien S, Hotton EJ, Lenguerrand E, et al. The ASSIST Study—-The BD Odon device for assisted vaginal birth: a safety and feasibility study. Trials. 2019;20(1):1.

62. Draycott TJ, Di Renzo GC. The role of operative vaginal birth in the 21st century and a way forward. BJOG. 2017;124(Suppl 4):5-6.

\section{Publisher's Note}

Springer Nature remains neutral with regard to jurisdictional claims in published maps and institutional affiliations.
Ready to submit your research? Choose BMC and benefit from:

- fast, convenient online submission

- thorough peer review by experienced researchers in your field

- rapid publication on acceptance

- support for research data, including large and complex data types

- gold Open Access which fosters wider collaboration and increased citations

- maximum visibility for your research: over $100 \mathrm{M}$ website views per year

At BMC, research is always in progress.

Learn more biomedcentral.com/submissions 